\title{
Application of Enterococcus Faecalis FK-23 in Fattening of the Japanese Black Cattle
}

\author{
Qingzhu Yuan (Corresponding author), Yoshihisa Kitamura, Takashi Shimada \& Takao Nohmi \\ Central Research Laboratories, Nichinichi Pharmaceutical Co., Ltd.
}

Mie 518-1417, Japan

Tel: 81-595-48-0201Ｅ-mail: yqz5012001@yahoo.com.cn

Ren $\mathrm{Na}$

Development \& Service Centre of Cow Industrialization

Xilinhaote, Inner Mongolia 026000, China

Xiao Jin

Animal Hygiene Supervision Place of Inner Mongolia

Huhehaote, Inner Mongolia 010015, China

Yoshihisa Kitamura \& Takashi Shimada

China-Japan Collaborating Centre for Probiotics Research

Nanjing Medical University, Nanjing, Jiangsu 210029, China

\begin{abstract}
Objective: By investigating the effects of feeding Enterococcus faecalis FK-23 preparation to Japanese Black cattle in the late fattening period, this paper discusses the increased value of beef and the feasibility. Method: 10 beef cattle were grouped into the Test Group and the Control Group, 5 beef cattle in the Test Group were fed E. faecalis FK-23 preparation at $8.0 \mathrm{~g}$ per day per head. The experiment included weight measure, blood test for White Blood Cell (WBC), Vitamin A (VA), Vitamin E (VE), Total Cholesterol (TC), glutamic oxaloacetic transaminase (GOT), blood urea nitrogen (BUN) and blood glucose (GLU), and HPLC test for fatty acid composition in neutral fat. Results: Comparing to the Control Group, the Test Group had excessive appetite, appreciable increase of daily gain (DG) ( $<<0.05$ ), appreciable increase of serum VE and TC $(\mathrm{p}<0.05)$, about the same level of VA, and obvious tendency of increased fatty acid in neutral fat, and showed an end weight increase of $4.3 \%$ and carcass weight increase of $9.3 \mathrm{~kg}$. Conclusion: Feeding E. faecalis FK-23 preparation to Japanese Black cattle in the late fattening period adds additional value to the beef cattle and improves its productivity.
\end{abstract}

Keywords: Enterococcus faecalis FK-23, Anti-oxidation, Meat quality, Fattening, Vitamin A, Vitamin E

\section{Introduction}

In Japan, the quality grade of beef determines the price of carcass; especially BMS (Beef Marbling Standard) number contributes $80 \%$ of the decision-making factors (Hirooka, H., 1998, p. 22-28). In order to increase BMS number, VA is usually controlled in fattening. There are abundant reports on the correlation between BMS and serum VA concentration. Recently, it is believed that the meat with the best quality, i.e. so called marbled beef with the ideal BMS number, can be obtained when serum VA concentration of cattle is kept at lower level from month $15^{\text {th }}$ to month $24^{\text {th }}$ (Nade, T., 2007, p. 161-166; Okumura, T., 2006, p. 387-393; Nakanishi, N., 2002, p. 273-282; Oka, A., 1998, p. 90-99). In addition, influencing factors, such as Vitamin E, Vitamin C, Se, cholesterol and genetic gene, are also widely reported (Nade, T., 2008, p. 495-466; Watanabe, D., 1999, p. 119-128; Noguchi, T., 1978, p. 125-130; Mitsumoto, M., 1992, p. 47-53; Watanabe, D., 1999, p. 195-202; Ichijo, S., 1993, p. 109-114; Buckley, D. J., 1989, p. 1193-1197; Itoh, M., 2003, p. 
43-49; Oka, A., 1999, p. 137-144; Mori, M., 2006, p. 15-19). New functions of VE found by Evans et al, the so-called fertility vitamin, have recently received continuous attentions. The meat quality of cattle with low concentration of serum VA, but continuously low concentration of TC and VE, is not good (Watanabe, D., 1999, p. 119-128). VE, existing in the membrane lipid of organism, can prevent membrane lipid from peroxidation (Noguchi, T., 1978, p. 125-130). It also has strong anti-oxidation and may maintain freshness of meat (Mitsumoto, M., 1992, p. 47-53), and can protect liver (Watanabe, D., 1999, p. 195-202), prevent muscle from denaturation (Ichijo, S., 1993, p. 109-114), etc. It is believed that oxidation of meat begins with lipid-rich membrane (Buckley, D. J., 1989, p. 1193-1197). By combining with radical after entering into cell membrane, the VE directly inhibits oxidation of pigment and lipid, as well as indirectly keeps reduction activity of Metmyoglobin to maintain the color of meat and the stability of lipid (Mitsumoto, M., 1992, p. 47-53). TC concentration in the late fattening period exhibits a significant positive correlation with BMS number, carcass weight (CWT), rib-eye area and rib thickness (RT), but a significant negative correlation with BCS (Beef Color Standard) number (Itoh, M., 2003, p. 43-49). Although lowering serum VA concentration can increase BMS, cattle thereupon develops the symptoms of VA deficiency, such as anorexia, blindness, ataxia and etc., in turn uptakes less feed and feed efficiency decreases (Oka, A., 1999, p. 137-144). However, researches on the color of meat directly related to the benefits of manufacturer and consumer are still lagging behind.

Lactic acid bacteria E. faecalis FK-23 strain comes from intestine of healthy individuals. The heat-processed product (FK-23 preparation) has tumor resistance (Ohasi, K., 1993, p. 396-399), infection resistance (Nohmi, T., 1996, p. 323-328), as well immunity activation (Ohashi, K., 1992, p. 919-925; Hasegawa, T., 1996, p. 103-112; Kanasugi, H., 1996, p. 563-565), etc. It is safe and non-toxic (Shimada, T., 1998, p. 53-60).

By feeding FK-23 preparation to Japanese Black cattle in the late fattening period, we investigated the effects of FK-23 preparation on the fattening and meat quality grade, assessed the added value of beef, and studied the practical applications of FK-23 preparation in the fattening of Japanese Black cattle.

\section{Materials and methods}

\subsection{Materials}

This experiment was carried out at the fattening farm of Japanese Black cattle in Mie Iga City from October 2006 to April 2007. 10 female Japanese Black cattle in the late fattening period, same habitat, same paternal line, 22 months old, were grouped into the Test Group ( 5 cattle) and the Control Group (the other 5 cattle). Fattening feed and fattening procedure were in accordance with the established procedure of the farm. FK-23 preparation is a dried dead bacteria powder of heat-processed pure E. faecalis FK-23 strain, provided by Nichinichi Pharmaceutical Co., Ltd. (Japan).

\subsection{Methodology}

Begin with body weight determination and venous blood collection of both groups, feed the Test Group with FK-23 preparation mixed into feed at $8.0 \mathrm{~g}$ per day per head; then collect venous blood once every month and weigh once every three months. At the time of slaughtering after six months of experiment, test carcass weight, collect subcutaneous adipose and renal adipose, and determine the quality grade of meat. Based on the blood morphology, count the white blood cell with a fully-automatic MEK-6258 White Blood Cell Counter manufactured by Nihon Kohden Corporation of Japan and test. the white blood cell percentage with an Olympus AH-3 optical microscope. Based on the blood biochemical analysis, test VA and VE with Shimadzu LC-6A HPLC made in Japan under the conditions that column is Shim-pack CLC-ODS $(6 \times 150 \mathrm{~mm})$, liquid phase is methanol, flow rate is $1.5 \mathrm{~mL} / \mathrm{min}$, and detection wavelength is $326 \mathrm{~nm}$. Determine total cholesterol (TC), glutamic oxaloacetic transaminase (GOT), blood urea nitrogen (BUN) and glucose (GLU) by colorimetric assay on Fuji Dry Chem 3000V from Japan respectively with TCHO-P III Kit Fuji Dry Chem slide from Japan, GOT/AST-P III Kit Fuji Dry Chem slide from Japan, BUN-PIII Kit Fuji Dry Chem slide from Japan and GLU-P III Kit Fuji Dry Chem slide from Japan. Test the composite and the weight percentage of fatty acid in subcutaneous adipose and renal adipose by GC method with Shimadzu GC-2010, wherein the saturated fatty acid includes myristic acid, palmitic acid and stearic acid, and the unsaturated fatty acid includes myristoleic acid, palmitoleic acid, oleic acid, linoleic acid and linolenic acid.

Compare and study the differences of carcass assessment results between the Test Group and the Control Group based on the appraisal report of meat quality grade from Japanese Meat Grading Association.

Based on the statistical analysis, take analysis of variance on the changes of body weight, daily gain, VA concentration and VE concentration with StatView Ver.5.0 from SAS Institute of Japan; carry out the two group paired-samples t-test and compute the Pearson's Correlation Coefficient of blood biochemical experimental data.

\section{Results}

\subsection{Body weight and daily gain (DG)}

There are no significant statistical differences $(\mathrm{p}>0.05)$ in body weight change and daily weight gain between two groups. However, the test group, after having taken FK-23 preparation for three months, has the trend that its daily gain 
is greater than the control group's ( $\mathrm{p} 1=0.20$ and $\mathrm{p} 2=0.19$ ) (Table 1 ).

\subsection{Experiments based on the blood morphology and blood biochemical analysis}

The test result based on the blood morphology does not show any abnormality. The results of t-test and Pearson's Correlation Coefficient based on the blood biochemical analysis indicate that there are significant statistical differences $(\mathrm{p}<0.05)$ in VE concentration (Figure 1) and no statistical differences $(\mathrm{p}>0.05)$ in VA, GOT, BUN, GLU and WBC (Table 2) between two groups. Table 3 exhibits the Correlation Coefficient (r) between two groups resulted from the correlation analysis of blood biochemical data. From table 3, we can see a low positive correlation $(\mathrm{r}=0.250)$ between VA and VE of the Control Group and a low negative correlation $(\mathrm{r}=-0.214)$ between VA and VE of the Test Group. Although there are no statistical differences $(\mathrm{p}>0.05)$ in TC concentration between the Test Group and the Control Group, TC concentration of the Test Group shows a gradual increasing tendency. In the Control Group, VA shows a low negative correlation with GOT $(\mathrm{r}=-0.352)$ and BUN $(\mathrm{r}=-0.241)$; VE shows a positive correlation with TC $(\mathrm{r}=0.532)$, a low positive correlation with WBC ( $\mathrm{r}=0.212)$, no significant correlation with GOT, BUN and GLU $(\mathrm{r}<|0.20|)$; TC shows a low positive correlation with GOT $(\mathrm{r}=0.362)$ and GLU $(\mathrm{r}=0.291)$; GOT shows a low positive correlation with GLU $(\mathrm{r}=0.331)$ and $\mathrm{WBC}(\mathrm{r}=0.267)$; BUN shows a low negative correlation with GLU $(\mathrm{r}=-0.362)$, a positive correlation with WBC $(\mathrm{r}=0.325)$. In the Test Group, VE shows a positive correlation with TC $(\mathrm{r}=0.763)$, no significant correlation with GOT, BUN, GLU and WBC $(\mathrm{r}<|0.20|)$; TC shows a low positive correlation with BUN $(\mathrm{r}=0.360)$, a low negative correlation with GLU ( $\mathrm{r}=-0.331)$; GOT shows a low negative correlation with BUN ( $\mathrm{r}=-0.212)$ and GLU $(\mathrm{r}=-0.410)$, a positive correlation with WBC $(\mathrm{r}=0.687)$; BUN shows a negative correlation with GLU $(\mathrm{r}=-0.528)$ and WBC $(\mathrm{r}=-0.321)$.

\subsection{Analysis on the composite of fatty acid}

There are no statistical differences $(\mathrm{p}>0.05)$ in saturated fatty acid and unsaturated fatty acid of neutral fat between two groups. But the proportion of unsaturated fatty acid in both subcutaneous adipose and renal adipose of the Test Group shows increasing tendency (Table 4).

\subsection{Carcass assessment score}

There are no statistical differences $(\mathrm{p}>0.05)$ in carcass weight and meat quality grade between two groups. But the carcass weight, rib-eye area, yield estimated percentage and rib thickness of the Test Group is higher than these of the Control Group (Table 5).

\section{Conclusion and discussion}

Although controlling intake of serum VA can increase BMS, cattle thereupon may develop typical symptoms of VA deficiency, such as night vision blindness, weight loss, limbs edema, etc. It in turn has a strong negative impact on fattening effectiveness and markedly decreases the value of carcass (Yano, H., 2004, p. 79-104). Influence of VA to the weight gain includes not only food intake, but also feed efficiency (Oka, A., 1999, p. 137-144). Feeding with food lack of VA for a long time may cause the decrease of VA concentration in blood and liver, and decrease of albumin and cholesterol. Moreover, it may have a negative effect on the quality of beef (Hodate, K., 1999, p. 22-28).

Physiological activity of VE can be summarized in the following aspects: (1) Anti-oxidation. Capturing the active oxygen resulted from oxidation of highly unsaturated fatty acid in lipid assures the normal functions of cell. (2) Anti-aging. Located near to the phospholipid membrane in biofilm structure of cell, VE can keep the safety of biofilm by preventing lipid from oxidation and resist aging. (3) Enhancement of Immunity. VE can enhance the defense response of body, the response of humoral immunity (increase of $\operatorname{IgG}$ ) and cellular immunity (increase of mitogen) to the lymphocyte stimulation, the phagocytosis and bactericidal effect of eosinophils, and the immunity by reducing the cortisol of body. (4) Regulation of endocrine. Activate pituitary gland and adrenal gland to secrete hormones. (5) Improvement of blood circulation. Activate microcirculation to prevent ischemia (Ichijo, S., 1993, p. 109-114). Food intake has a major effect on serum VE and TC, in turn affects the quality of beef. Therefore, it is necessary to enhance the control of nutrition of cattle to improve the meat quality (Watanabe, D., 1999, p. 119-128).

Mayanagi, A. et al (1994, p. 39-47) reported that the fattening method of lowering VA concentration may easily cause VA deficiency and decrease the concentration of VE in blood, observed mainly in the appearance of liver function damage and pneumonia. After slaughtering, the amount of abandoned livers due to abscess, necrosis, etc. showed a negative correlation with VE concentration in blood. Therefore, it is necessary to keep optimal serum VA and VE concentration in blood to improve reproduction and disease resistance of cattle, and establish an economic and effective fattening system.

Mitsumoto, M. et al (1991, p. 1489-1492; 1995, p. 2289-2294) reported that VE, with its strong anti-oxidation, could prevent raw beef from fading and lipid from oxidation during deepfreeze or exhibition. Intake of FK-23 preparation could stabilize the color and lipid of raw beef. This method is safe, practical, and has huge industrialization significance.

Watanabe, D. (1999, p. 119-128) proposed that serum TC concentration of ranch herd with high A5-occurrence rate was 
higher than $130 \mathrm{mg} / \mathrm{dl}$. Yano, H. et al (2004, p. 79-104) suggested that serum TC concentration showed a positive correlation with BMS. Serum TC concentration of cattle with higher meat quality grade had increased continuously within 20 months or longer. Therefore, serum TC concentration is considered as an index for evaluating the meat quality. For the Test Group in this study, serum TC concentration has gradually increased to $193 \mathrm{mg} / \mathrm{dl}$ after having FK-23 preparation for two months. It indicates that intake of bacteria preparation with high amount of lipid has an indirect positive effect on BMS number, carcass weight, rib-eye area, rib thickness and BCS number.

This study was carried out under the strict control of VA concentration. The horizontal translocation of VA concentration (Figure 1) indicates that intake of FK-23 preparation does not have any effect on VA concentration. There are no statistical difference $(\mathrm{p}>0.05)$ in body weight and daily gain between two groups. However, after three months of experiment, the Test Group shows a tendency that its daily gain is higher than that of the Control Group. Meanwhile, the average end weight of the Test Group is $4.3 \%$ higher than that of the Control Group; and its average carcass weight is $9.3 \mathrm{~kg}$ higher than that of the Control Group (Table 1). It is believed that FK-23 preparation can relieve or ameliorate the symptoms such as anorexia and decrease of feed intake due to VA deficiency during the fattening process of Japanese Black cattle. Comparing to the Control Group, VE concentration of the Test Group shows a markedly increasing tendency, and has statistical significance $(\mathrm{p}<0.05)$. Other relevant correlation analysis results demonstrate that the Correlation Coefficients ( $r$ ) of VE with VA and TC of the Control Group are 0.205 and $0.532(p<0.05$ ) respectively; while these of the Test Group are -0.214 and $0.763(\mathrm{p}<0.05)$ respectively. VE of the Control Group shows a low positive correlation with VA; however becomes a low negative correlation with VA after having FK-23 preparation. This indicates that VE concentration decreases with the decrease of VA concentration during common fattening procedure; however, after having FK-23 preparation, VE concentration still keeps an increasing tendency even if VA concentration decreases. VE concentration significantly correlates with TC concentration in both groups, there are statistical differences $(\mathrm{p}<0.05)$ both in VE and TC between two groups, and their correlation in the Test Group is higher than that in the Control Group. In addition, BUN has a Correlation Coefficient of -0.362 and -0.528 ( $p<0.05$ ) with GLU respectively in the Control Group and the Test Group; GOT has a Correlation Coefficient of 0.267 and 0.687 ( $p<0.05$ ) with WBC respectively in the Control Group and the Test Group. All above correlation analysis results prove that feeding FK-23 preparation to Japanese Black cattle in the late fattening period can not only improve serum VE and VC concentration, but also enhance the relation among the correlated indexes. But its mechanism is still unknown.

The analysis on the composite of fatty acid demonstrates that there are no statistical differences $(p>0.05)$ in the composite of fatty acid in both subcutaneous adipose and renal adipose between the two groups. But the proportion of unsaturated fatty acid of the Test Group shows an increasing tendency (Table 4). In subcutaneous adipose, the proportion of oleic acid, a component of soft adipose with low melting point $\left(13.3{ }^{\circ} \mathrm{C}\right)$, increases by $0.8 \%$. Oleic acid has the functions of anti-arteriosclerosis, anti-oxidation, anti-hypertension, anti-aging, anti-senile dementia, anti-constipation, resisting coronary heart disease, inhibiting low density lipoprotein, etc; the proportion of Myristoleic acid, another component of soft adipose, increases by $1.0 \%$. On the other hand, the proportion of palmitic acid, a component of hard adipose with high melting point $\left(82.9{ }^{\circ} \mathrm{C}\right.$ ), decreases $0.6 \%$. The total rate of change is $1.2 \%$. The total rate of change of components of fatty acid in renal adipose is $2.6 \%$. The melting point of adipose shows a high correlation with the composite of fatty acid, a negative correlation with unsaturated fatty acid, a positive correlation with saturated fatty acid (Kobayashi, M., 2006, p. 521-527). The proportion of unsaturated fatty acid has no relations with the amount of crude fat, body weight, height and BMS number, but is seriously affected by the breeding bull. Partial substitution of the fine fodder has some effects on the composite of fatty acid in renal adipose, but has no effect on daily weight gain and carcass characteristics (Shinoda, M., 2007, p. 201-208). BMS and carcass characteristics show independent genetic correlations with the melting point and composite of fatty acid (Inoue, K., 2008, p. 1-8). This study was carried out on the same patrilineal Japanese Black cattle under the same conditions of fattening in the same fattening time. The increase of the proportion of unsaturated fatty acid is believed to be correlative with intake of FK-23 preparation, but does not have any effect on the carcass characteristics.

There are no statistical differences $(p>0.05)$ in quality grade of carcass, BMS and other evaluation results of meat quality between two groups. But the carcass weight, rib-eye area, yield estimated percentage and rib thickness of the Test Group is slightly higher than these of the Control Group. The proportion of unsaturated and saturated fatty acid has minor change, but its effects can not be identified by naked eyes of the meat appraisers. It has not been reported so far as to the change range of proportion that affects meat evaluation grade and mouthfeel. Therefore, it is important to study the chemical components that affect the flavors and flavor developments of marbled beef.

Feeding FK-23 preparation to Japanese Black cattle in the late fattening period can increase serum VE and VC concentration, improve appetite and feed intake, as well as increase daily gain, end weight and carcass weight. It has some minor effects on adipose characteristics in body, but the proportion of unsaturated fatty acid shows an increasing tendency. Therefore, FK-23 preparation not only increase the economic benefit of fattening farm, but also has no negative effect on the traditional fattening system that depends on controlling VA concentration in feed to obtain marbled beef with the most ideal BMS number. VE-rich meat has a longer shelf time and color retention because of 
anti-oxidation of VE. Such a meat with above additional values should be favored by consumers and market. In this study, VE-rich beef is obtained by feeding FK-23 preparation. It is proved that FK-23 preparation can increase the beef's additional value and improve its productivity in the late fattening period of Japanese Black cattle. The effects on the meat tenderness and flavor from the point of view chemical composites should be studied in the future.

\section{Acknowledgements}

The study is completed with the help of Mori Masaaki, a scientist from the Research Department of Livestock Products at the Science and Technology Promotion Center in Mie of Japan. Blood collection is supported by Fukuura Hirosaki et al, veterinarians from the Hygiene Service Center of Iga Branch Station at the National Institute of Animal Health in Mie of Japan. I would like to express my sincere appreciation to Mr. Mori Masaaki and Mr. Fukuura Hirosaki for their guidance and support.

\section{References}

Buckley, D. J., Gray. J. I., Asghar, A., Price, J. F., Crackel, R. L., Booren, A. M., Pearson, A. M. \& Miller, E. R. (1989). Effects of dietary antioxidants and oxidized oil on membranal lipid stability and pork product quality. Journal of Food Science, 54, 1193-1197.

Hasegawa, T., Kanasugi, H., Hidaka, M., Yamamoto, T., Abe, S. \& Yamaguchi, H. (1996). Effect of administered heat-killed Enterococcus faecalis FK-23 preparation neutropenia in dogs treated with cyclophosphamide. Int. J. Immunopharmac., 18(2), 103-112.

Hirooka, H. \& Matumoto, M. (1998). Main factors affecting the price of cattle carcass in the carcass market of Japan. Japanese Journal of Rural Economics, 67, 22-28.

Hodate, K. (1999). Control on VA and improvement of meat quality in fattening cattle. Society of Beef Cattle Science, $67,22-28$.

Horii, M., Sakurai, Y., Kanbe, Y., Kasai, K., Ono, K., Asada, T., Mori, T., Kobayashi, M., Iguchi, A., Yamada, M., Hayashi, M. \& Hodate, K. (2009). Relationship between Japanese beef marbling standard numbers and intramuscular lipid in M. longissimus thoraces of Japanese Black steers from 1996 to 2004 . Japanese Society of Animal Science, 80(1), 55-61.

Ichijo, S. (1993). Significance of VE and Se to livestock. Journal of the Veterinary Medicine, 46(2), 109-114.

Inoue, K., Shoji, N. \& Kobayashi, M. (2008). Genetic relations fat melting point fatty acid composition and carcass traits Japanese Black Cattle. Japanese Society of Animal Science, 79(1), 1-8.

Itoh, M. \& Hirooka, H. (2003). Relationships of serum Vitamin A and total cholesterol concentrations with carcass traits in crossbreds between Japanese Black and Holstein. Japanese Society of Animal Science, 74(1), 43-49.

Kanasugi, H., Hasegawa, T., Yamamoto, T., Abe, S. \& Yamaguchi, H. (1996). Optimal dose of Enterococcal preparation (FK-23) supplemented perorally for stimulation of leukocyte reconstitution in dogs treated with cyclophosphamide. Journal of Veterinary Medical Science, 58(6), 563-565.

Kobayashi, M. \& Shoji, N. (2006). Chemical characteristics and palatability molecular species of triacylglycerol obtained from Japanese Black Cattle body fat. Japanese Society of Animal Science, 77(4), 521-527.

Mayanagi, A., Fuyuki, T. \& Toratani, T. (1994). Marketing rate and change of blood composite in fattening Japanese Black cattle. Journal of Clinical Veterinary Medicine, 12(5). 39-47.

Mitsumoto, M. (1992). VE, VC and fresh keeping of beef. Animal Husbandry, 46(9), 47-53.

Mitsumoto, M., Arnold, R. N., Schefer, D. M. \& Cassens, R. G. (1995). Dietary vitamin E supplementation shifted weight loss from drip to cooking loss in fresh beef longissimus during display. Japanese Society of Animal Science, 73, 2289-2294.

Mitsumoto, M., Cassens, R. G., Schefer, D. M., Arnold, R. N. \& Scheller, K. K. (1991). Improvement of color and lipid stability in beef longissimus and dietary vitamin E and vitamin C treatment. Journal of Food Science, 56, 1489-1492.

Mori, M., Padilla, L., Matsui, T., Yano, H., Matsui, Y. \& mada, H. (2006). Effects of Vitamin C supplementation on plasma Vitamin C level and fattening traits in Japanese Black cattle on a fattening farm. Society of Beef Cattle Science, 81, 15-19.

Ohasi, K., Satonaka, K., Yamamoto, T., Yamazaki, M., Kimura, S., Abe, S. \& Yamaguchi, H. (1993). Antitumor activity of Enterococcus faecalis FK-23 preparation against murine syngeneic tumors. Journal of the Pharmaceutical Society of Japan, 113(5), 396-399.

Nade, T. (2008). Factors affecting carcess composition and simple technique for the evaluation of carcass composition in Japanese Black cattle. Japanese Society of Animal Science, 79(4), 495-466.

Nade, T., Masuda, Y., Misumi, S. \& Fujita, K. (2007). Effects of Vitamin A restriction on growth and carcass 
characteristics of Japanese black steers measured by ultrasonic equipment. Japanese Society of Animal Science, 78(2), 161-166.

Nakanishi, N., Yamada, T., Mitsumoto, M., Mitsuhashi, T., Aikawa, K., Muramoto, T. \& Ozawa, S. (2002). Effects of Vitamin A on the meat productivity of Japanese Black Steers. Japanese Society of Animal Science, 73(2), 273-282.

Noguchi, T. (1978). The newest idea in the biochemical functions of VE and Se in body. Proceedings of Japanese Society for Animal Nutrition and Metabolism, 22(2), 125-130.

Nohmi, T., Abe, S., Katoh, M., Yamamoto, T. \& Yamaguchi, H. (1996). Augmented ability of spleen cells to produce interferons and prevention from lethal infection of herpes simplex virus in mice orally treated with Enterococcus faecalis preparation, FK-23. Journal of the Pharmaceutical Society of Japan, 116(4), 323-328.

Ohashi, K., Ueda, H., Yamazaki, M., Kimura, S., Abe, S. \& Yamaguchi, H. (1992). Activity of Enterococcus faecalis (FK-23) preparation as a biological response modifier. Journal of the Pharmaceutical Society of Japan, 112(12), 919-925.

Oka, A. (1999). Feeding of beef cattle and VA. Japanese Society for Animal Nutrition and Metabolism, 43(2), 137-144.

Oka, A. (1999). Feeding technology for fattening Japanese Black cattle and VA. Journal of Clinical Veterinary Medicine, 17(11). 16-18.

Oka, A., Dohgo, T., Juen, M. \& Saito, T. (1998). Effects of Vitamin A on beef quality, weight gain, and serum concentrations of thyroid hormones, insulin-like growth factor-I, and insulin in Japanese black steers. Japanese Society of Animal Science, 69(2), 90-99.

Okumura, T., Nade, T., Saito, K., Misumi, S., Masuda, Y., Sakuma, H., Fujita, K. \& Kawamura, T. (2006). The effects of undergoing low Vitamin A concentration for varying periods on carcass characteristics in Japanese black steers. Japanese Society of Animal Science, 77(3), 387-393.

Shimada, T., Ito, K., Iwatani, K. \& Yamamoto, T. (1998). A 4-week repeated dose oral toxicity study Enterococcus faecalis FK-23 preparation (FK-23) in rats. Pharmacometrics, 55(2/3), 53-60.

Shinoda, M., Kushibiki, S., Singuu, H., Ueda, Y., Thono, E. \& Murai, M. (2007). Effects of feeding whole crop rice silage during the later fattening stage growth, blood profiles and carcass traits Japanese Black steers. Japanese Society of Animal Science, 78(2), 201-208.

Watanabe, D. (1999). Correlation of fattening yield of Japanese Black cattle with serum VA, VE and total cholesterol. Proceedings of Japanese Society for Animal Nutrition and Metabolism, 43(2), 119-128.

Watanabe, D. (1999). Metabolism profile test on the fattened cattle. Diagnosis and Treatment System for Veterinarian: Part about Beef. Japanese Rural Culture Association. pp. 195-202.

Yano, H., Hirai, S. \& Kitagawa, M. (2004). Recent advances in research for nutritional physiology of beef cattle. Japanese Society for Animal Nutrition and Metabolism, 48(2), 79-104.

Table 1. Body weight change and daily gain of sample cattle (means \pm standard deviation)

\begin{tabular}{|c|c|c|c|c|}
\hline \multirow{2}{*}{ Time interval for measurement } & \multicolumn{2}{|c|}{ Changes of body weight $(\mathrm{kg})$} & \multicolumn{2}{|c|}{$D G(\mathrm{~kg})$} \\
\cline { 2 - 5 } & Control Group & Test Group & Control Group & Test Group \\
\hline At the time of introduction & $281 \pm 12$ & $281 \pm 8$ & ND & ND \\
\hline At the beginning of experiment & $551 \pm 33$ & $542 \pm 39$ & $0.69 \pm 0.06$ & $0.67 \pm 0.08$ \\
\hline After three months of experiment & $589 \pm 31$ & $598 \pm 28$ & $0.42 \pm 0.18^{*}$ & $0.62 \pm 0.12^{*}$ \\
\hline At marketing time & $636 \pm 40$ & $663 \pm 28$ & $0.53 \pm 0.22^{* *}$ & $0.72 \pm 0.14^{* *}$ \\
\hline
\end{tabular}

* represents $\mathrm{p} 1 ; * *$ represents $\mathrm{p} 2$; ND represents no test on it. 
Table 2. Test results based on blood biochemical analysis (means \pm standard deviation)

\begin{tabular}{|c|c|c|c|c|c|}
\hline & Item & Month zero & Month $2^{\text {nd }}$ & Month $4^{\text {th }}$ & Month $6^{\text {th }}$ \\
\hline \multirow{7}{*}{$\begin{array}{l}\text { Control } \\
\text { Group }\end{array}$} & VA & $65.3 \pm 6.9$ & $47.8 \pm 9.1$ & $42.2 \pm 7.1$ & $48.4 \pm 6.4$ \\
\hline & $\mathrm{VE}$ & $298.4 \pm 35.4$ & $255.7 \pm 16.9$ & $256.3 \pm 73.8$ & $319.3 \pm 85.6$ \\
\hline & $\mathrm{TC}$ & $147.6 \pm 35.1$ & $142.4 \pm 14.8$ & $134.0 \pm 21.2$ & $168.0 \pm 25.1$ \\
\hline & GOT & $60.0 \pm 6.0$ & $69.0 \pm 6.8$ & $62.0 \pm 7.5$ & $70.0 \pm 15.4$ \\
\hline & $\mathrm{BUN}$ & $18.6 \pm 2.3$ & $17.3 \pm 1.3$ & $20.1 \pm 3.4$ & $18.7 \pm 1.8$ \\
\hline & GLU & $67.0 \pm 2.8$ & $73.0 \pm 6.8$ & $62.0 \pm 4.0$ & $68.0 \pm 5.9$ \\
\hline & WBC & $9820 \pm 1110$ & $9220 \pm 1260$ & $8300 \pm 1470$ & $8720 \pm 1820$ \\
\hline \multirow{7}{*}{$\begin{array}{c}\text { Test } \\
\text { Group }\end{array}$} & VA & $60.4 \pm 14.2$ & $44.0 \pm 5.4$ & $43.8 \pm 7.3$ & $51.4 \pm 4.9$ \\
\hline & $\mathrm{VE}$ & $229.3 \pm 53.3$ & $203.5 \pm 73.8$ & $339.1 \pm 50.7$ & $386.1 \pm 44.0$ \\
\hline & $\mathrm{TC}$ & $130.0 \pm 25.1$ & $124.0 \pm 32.1$ & $166.0 \pm 15.2$ & $193.0 \pm 13.4$ \\
\hline & GOT & $70.0 \pm 15.3$ & $71.0 \pm 17.3$ & $71.0 \pm 14.8$ & $73.0 \pm 15.5$ \\
\hline & $\mathrm{BUN}$ & $17.1 \pm 2.5$ & $17.0 \pm 2.0$ & $21.1 \pm 4.9$ & $18.8 \pm 3.5$ \\
\hline & GLU & $65.0 \pm 4.8$ & $72.0 \pm 4.5$ & $58.0 \pm 4.2$ & $66.0 \pm 2.6$ \\
\hline & WBC & $8700 \pm 2390$ & $8160 \pm 1750$ & $7820 \pm 1530$ & $7920 \pm 1970$ \\
\hline
\end{tabular}

$\mathrm{n}=10$

Table 3. Correlations among test results based on blood biochemical analysis

\begin{tabular}{|c|c|c|c|c|c|c|c|c|c|c|c|c|}
\hline & $F-V A$ & $F-V E$ & $F-T C$ & $F-G O T$ & $F-B U N$ & $F-G L U$ & $C-V A$ & $C-V E$ & $C-T C$ & $C-G O T$ & $C-B U N$ & $C-G L U$ \\
\hline F-VA & - & -0.214 & 0.101 & -0.214 & 0.054 & 0.098 & & & & & & \\
\hline F-VE & -0.214 & - & $0.763^{*}$ & 0.042 & 0.186 & -0.088 & & & & & & \\
\hline F-TC & 0.101 & $0.763 *$ & - & 0.153 & 0.360 & -0.331 & & & & & & \\
\hline F-GOT & -0.214 & 0.042 & 0.153 & - & -0.212 & -0.410 & & & & & & \\
\hline F-BUN & 0.054 & 0.186 & 0.360 & -0.212 & - & $-0.528^{*}$ & & & & & & \\
\hline F-GLU & 0.098 & -0.088 & -0.331 & -0.410 & $-0.528 *$ & - & & & & & & \\
\hline F-WBC & -0.326 & 0.007 & 0.012 & $0.687^{*}$ & -0.321 & -0.189 & & & & & & \\
\hline C-VA & & & & & & & - & 0.250 & 0.018 & -0.352 & -0.241 & -0.163 \\
\hline $\mathrm{C}-\mathrm{VE}$ & & & & & & & 0.250 & - & $0.532 *$ & 0.029 & 0.045 & -0.006 \\
\hline C-TC & & & & & & & 0.018 & $0.532^{*}$ & - & 0.362 & -0.072 & 0.291 \\
\hline C-GOT & & & & & & & -0.352 & 0.029 & 0.362 & - & -0.025 & 0.331 \\
\hline C-BUN & & & & & & & -0.241 & 0.045 & -0.072 & -0.025 & - & -0.362 \\
\hline C-GLU & & & & & & & -0.163 & -0.006 & 0.291 & 0.331 & -0.362 & - \\
\hline C-WBC & & & & & & & 0.070 & 0.212 & 0.005 & 0.267 & 0.325 & 0.134 \\
\hline
\end{tabular}

* represents $\mathrm{p}<0.05$; C- represents the Control Group; F- represents the Test Group; WBC represents number of white blood cell; Correlation is represented by the Correlation Coefficient (r) of various index between the Test Group and the Control Group. 
Table 4. Analysis on the composite of fatty acid in body adipose (means \pm standard deviation)

\begin{tabular}{|c|c|c|c|c|c|c|c|c|c|}
\hline & & \multicolumn{3}{|c|}{ Saturated fatty acid (\%) } & \multicolumn{5}{|c|}{ Unsaturated fatty acid (\%) } \\
\hline \multicolumn{2}{|c|}{ Types of fatty acid } & $\begin{array}{l}\text { Myristic } \\
\text { acid }\end{array}$ & $\begin{array}{l}\text { Palmitic } \\
\text { acid }\end{array}$ & $\begin{array}{l}\text { Stearic } \\
\text { acid }\end{array}$ & $\begin{array}{c}\text { Linolenic } \\
\text { acid }\end{array}$ & $\begin{array}{l}\text { Myristoleic } \\
\text { acid }\end{array}$ & $\begin{array}{c}\text { Palmitoleic } \\
\text { acid }\end{array}$ & $\begin{array}{l}\text { Oleic } \\
\text { acid }\end{array}$ & $\begin{array}{c}\text { Linoleic } \\
\text { acid }\end{array}$ \\
\hline \multirow{4}{*}{$\begin{array}{c}\text { Subcutaneous } \\
\text { adipose }\end{array}$} & \multirow{2}{*}{$\begin{array}{l}\text { Control } \\
\text { Group }\end{array}$} & $2.1 \pm 0.2$ & $23.9 \pm 1.4$ & $5.2 \pm 0.9$ & $0.0 \pm 0.0$ & $2.5 \pm 0.3$ & $9.8 \pm 1.3$ & $54.2 \pm 2.5$ & $2.4 \pm 0.7$ \\
\hline & & \multicolumn{3}{|c|}{$31.3 \pm 2.3$} & \multicolumn{5}{|c|}{$68.9 \pm 2.3$} \\
\hline & \multirow{2}{*}{$\begin{array}{l}\text { Test } \\
\text { Group }\end{array}$} & $2.0 \pm 0.1$ & $23.3 \pm 0.7$ & $4.5 \pm 0.7$ & $0.0 \pm 0.0$ & $2.6 \pm 0.3$ & $9.8 \pm 1.0$ & $55.0 \pm 1.8$ & $2.7 \pm 0.4$ \\
\hline & & \multicolumn{3}{|c|}{$30.1 \pm 1.5$} & \multicolumn{5}{|c|}{$70.1 \pm 1.6$} \\
\hline \multirow{4}{*}{$\begin{array}{c}\text { Renal } \\
\text { adipose }\end{array}$} & \multirow{2}{*}{$\begin{array}{l}\text { Control } \\
\text { Group }\end{array}$} & $1.9 \pm 0.2$ & $24.4 \pm 1.7$ & $22.9 \pm 3.4$ & ND & $0.4 \pm 0.1$ & $1.7 \pm 0.3$ & $46.6 \pm 4.3$ & $2.0 \pm 0.5$ \\
\hline & & \multicolumn{3}{|c|}{$49.4 \pm 5.1$} & \multicolumn{5}{|c|}{$50.7 \pm 5.1$} \\
\hline & \multirow{2}{*}{$\begin{array}{c}\text { Test } \\
\text { Group }\end{array}$} & $1.8 \pm 0.4$ & $23.0 \pm 2.3$ & $21.8 \pm 3.1$ & ND & $0.4 \pm 0.1$ & $1.8 \pm 0.2$ & $48.9 \pm 5.3$ & $2.2 \pm 0.4$ \\
\hline & & \multicolumn{3}{|c|}{$46.8 \pm 5.4$} & \multicolumn{5}{|c|}{$53.3 \pm 5.4$} \\
\hline
\end{tabular}

$\mathrm{n}=10$; ND represents no test on it.

Table 5. Assessment on carcass (means \pm standard deviation)

\begin{tabular}{|c|c|c|}
\hline & Control Group & Test Group \\
\hline Carcass weight $(\mathrm{kg})$ & $393.0 \pm 30.0$ & $402.3 \pm 32.2$ \\
Quality Grade & $3.2 \pm 0.8$ & $3.6 \pm 0.5$ \\
\hline Rib-eye area $\left(\mathrm{cm}^{2}\right)$ & $57.3 \pm 8.7$ & $61.3 \pm 11.3$ \\
\hline RT (cm) & $6.9 \pm 0.5$ & $7.0 \pm 0.3$ \\
\hline SFT (cm) & $2.2 \pm 0.6$ & $1.8 \pm 0.7$ \\
\hline Yield estimated percentage (\%) & $74.6 \pm 1.3$ & $75.4 \pm 1.8$ \\
\hline BMS number & $4.0 \pm 1.4$ & $4.8 \pm 1.8$ \\
BCS number & $4.4 \pm 0.5$ & $4.8 \pm 0.8$ \\
\hline
\end{tabular}

$\mathrm{n}=10$; RT represents rib thickness; SFT represents subcutaneous fat thickness; BMS represents beef marbling score; $\mathrm{BCS}$ represents beef meat color score; BFS represents beef fat color score. 


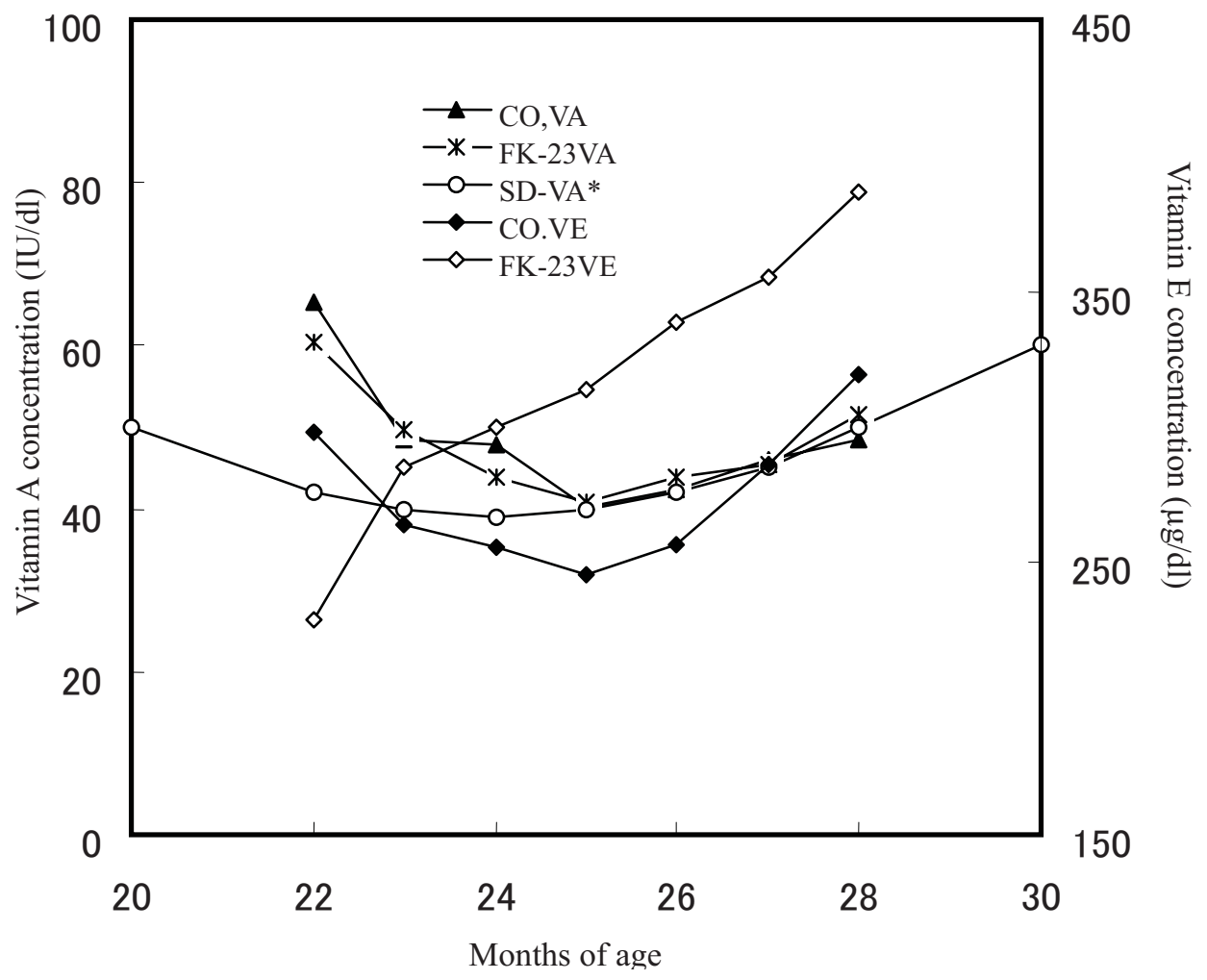

Figure 1. The effects of E. faecalis FK-23 preparation on serum VA concentration and VE concentration

Horizontal translocation result indicates that serum VA of the Test Group is similar to that of the Control Group, although decreases relatively late, finally reaches the standard level of concentration. After one month of experiment, VE has continuously increased until marketing time, and there is a significant statistical difference $(\mathrm{p}<0.05)$ in VE concentration between the Test Group and the Control Group.

FK-23 VA represents VA concentration of the Test Group; CO, VA represents VA concentration of the Control Group; SD-VA* represents the standard VA concentration in cattle blood popularized in fattening Japanese Black cattle (Oka, A., 1999, p. 16-18); FK-23VE represents VE concentration of the Test Group; CO, VE represents VE concentration of the Control Group. 